\title{
Anti-inflammatory effect on genes expression after four days of Qigong training in peripheral mononuclear blood cells in healthy women
}

\author{
Paweł Półrola ${ }^{1, A-F}$, Magdalena Wilk-Franczuk ${ }^{2, A-B, D-E}$, Jacek Wilczyński ${ }^{1, A, D, F}$, \\ Grażyna Nowak-Starz',C,F, Jolanta Góral-Półrola ${ }^{3, A-B, D-F}$, Grzegorz Chruściński ${ }^{4, C, F}$, \\ Iwona Bonisławska ${ }^{5, B-C, E-F}$, Agnieszka Pedrycz ${ }^{6, C, F}$, Małgorzata Żychowska ${ }^{7, A-F}$ \\ ${ }^{1}$ Faculty of Medicine and Health Sciences, Jan Kochanowski University, Kielce, Poland \\ ${ }^{2}$ Faculty of Health Sciences, Medical College, Jagiellonian University, Kraków, Poland \\ ${ }^{3}$ Old Polish University, Kielce, Poland \\ ${ }^{4}$ Department of Sport Management, Faculty of Physical Education, Gdansk University of Physical Education and Sport, \\ Gdańsk, Poland \\ ${ }^{5}$ Department of Physical Education, Faculty of Physical Education, Gdansk University of Physical Education and Sport, \\ Gdańsk, Poland \\ ${ }^{6}$ Department of Histology and Embryology and Experimental Cytology Unit, Medical University, Lublin, Poland \\ ${ }^{7}$ Department of Life Sciences, Faculty of Physical Education, Gdansk University of Physical Education and Sport, Gdańsk, \\ Poland
}

A - Research concept and design, B - Collection and/or assembly of data, C - Data analysis and interpretation,

$D$ - Writing the article, $E$ - Critical revision of the article, F-Final approval of article

\begin{abstract}
Półrola P, Wilk-Franczuk M, Wilczyński J, Nowak - Starz G, Góral-Półrola J, Chruściński G, Bonisławska I, Pedrycz A, Żychowska M. Antiinflammatory effect on genes expression after four days of Qigong training in peripheral mononuclear blood cells in healthy women. Ann Agric Environ Med. 2018; 25(2): 329-333. doi: 10.26444/aaem/85208
\end{abstract}

\section{Abstract}

Introduction. Some studies have shown the influence of Qigong on gene expression in different cells, but there is little data associated with the influence of this kind of therapy on genes expression in pheripheral monocellucar blood cells.

Objective. The aim of this study was to evaluate changes in the expression of genes associated with cellular stress response in peripheral mononuclear blood cells (PMBC) in healthy women.

Materials and method. The experiment took place at the Japanese Martial Arts Centre "DOJO" in Stara Wieś, Poland, conducted over the course of a 4-day qigong training session. To evaluate the genes effect of this training, blood samples were taken before and after the training period. This experiment involved 20 healthy women (aged 56.2 \pm 9.01 , body height $164.8 \pm 6.5$ and mass $65.5 \pm 8.2$ ). To determine the expression of HSF-1, HSPA1A, NF-kB, IL10 and CCL2 mRNA, 3 ml of venous blood was collected. The blood samples were placed in tubes allowing for separation (BD Vacutainer CPT ${ }^{\mathrm{TM}}$ ) before and after the 4 days of qigong training. Isolated PMBC were used to determine gene expression using real-time qRT-PCR (quantitative reverse transcription polymerase chain reaction).

Results. Significant decreases in NF-kB and CCL2 mRNA and increases in IL10, HSF1 and HSPA1A m-RNA were detected after 4 days of qigong training. The obtained findings suggest that qigong caused a reduction in the inflammatory and intensified anti-inflammatory gene expression, as well as a higher expression of HSF-1 and HSPA1A.

Conclusion. The adaptive response to qigong training was similar to the adaptive response to physical activity and was detected through gene expression in PMBC. Furthermore, this kind of training is especially indicated for women because of their higher susceptibility to psychosocial stress when compared to men.

\section{Key words}

qigong, genes expression, heat shock protein, inflammation

\section{INTRODUCTION}

Modern lifestyles represent an enormous challenge for our bodies. Time constraints, stress, lack of sleep, and environmental pollution are all factors exerting pressure on the nervous, endocrine, and cardiovascular systems, including gene activity. Qigong is one method of exercise belonging to the category of mind-body therapy (MBT). According to Astin et al. [1], MTB can influence human

Address for correspondence: Małgorzata Żychowska, The Gdansk University of Physical Education and Sport, Department of Sport Management, Gdańsk, Poland, Górskiego, 1, 80-336 Gdańsk, Poland

e-mail: zychowska.m@gmail.com

Received: 05.12.2017; accepted: 11.02.2018; first published: 23.03.2018 health and is an important part of unconventional medicine. Current subject literature shows a plethora of data that has demonstrated the positive impact of MBT on human health [2-4]. Recently, the healthy effects of qigong have been better documented regarding its application in maintaining wellness [5, 6]. Loucks et al.[7] reported that this type of exercise has a positive impact on the cardiovascular system and is helpful in smoking cessation, as well as the stabilization of body mass. Types of exercise, including qigong, have been introduced in the training and rehabilitation of older people. For this group, qigong can improve balance, agility, muscular strength and reduce the risk of falls $[4,5]$. It is also useful in reducing the symptoms of restless legs syndrome [8]. There are some reports on $\mathrm{MBT}$ in which the cytotoxic effect on 
cancer cells has been analysed, including the tumour cells of the pancreas [9] and breast cancer cells [10], as well usefulness in stuttering therapy [11].

Psychosocial stress results in increased inflammatory markers in the blood, i.e., interleukin 6(IL6), CCL2, C-reactive protein (CRP), E-selectin and molecule of intercellular adhesion-1 [12, 13]. Therefore, the researchers' interest was also related to the influence of MBT, including qigong, on the reduction of inflammatory gene activity [14-17]. The most popular experiments are those in which proinflammatory interleukins are detected. Li et al. [18] reported that qigong training can enhance the immune response, resolution of inflammation, and downregulation of cellular metabolism in neutrophil transcription. Furthermore, in a study involving patients with early stage breast cancer, Antoni et al. [19] reported a decrease in GATA transcription factors and NF-B/Rel activity, and an increase in the interferon response to glucocorticoid receptor activity. A decrease in $N F-k B$ activity in leukocytes after MBT was also indicated by Black et al. [20], Creswell et al. [21] and Bower et al. [22] Moreover, Kaliman et al. [23] reported a decrease in the proinflammatory cytokine gene expression after mindful meditation in peripheral blood mononuclear cells.

In the subject literature, studies of genes associated with apoptosis following qigong are relatively rare. Sharma et al. [24], along with Sudarshan Kriya, reported the upregulation of the expression of genes related to survival from oxidative stress. Despite data showing the positive impact of qigong training [18], little is known about the impact of this training on gene expression in PMBC associated with stress response.

\section{OBJECTIVE}

The aim of this study was to evaluate changes in the expression of HSF1, HSPA1A, IL6, IL10, CCL 2 and NF- $k B$ mRNA in healthy women. It was assumed that the prohealth effect would be similar to those obtained by physical exercise, noticeable through decreases in NF-kB, IL6 and CCL $2 \mathrm{mRNA}$, increases in IL10 mRNA, and increases in HSF1 and HSPA1A mRNA. To the best of the authors' knowledge, CCL2 expression after MBT has not been subsequently evaluated, although it is important in the pathogenesis of several diseases, such as psoriasis, rheumatoid arthritis and atherosclerosis [25].

\section{MATERIALS AND METHOD}

Participants and ethics. A total of 20 healthy women aged $56.2 \pm 9.01$, body height $164.8 \pm 6.5$, body mass $65.5 \pm 8.2$ and body mass index (BMI) 24.2 \pm 3.1 , participated in the experiment. All subjects had a normal health status over the course of the 2 months of the study (no drugs, alcohol, nicotine, negative medical history, etc.). Additionally, they were subject to a physical examination and gave consent for their participation in the experiment.

The study was approved by the Bioethics Committee for Clinical Research at the Regional Medical Chamber in Gdańsk, Poland, and conducted according to the Declaration of Helsinki. All participants gave their written consent to participate in the study and were informed about the purpose and test procedures. Additionally, they were made aware of the possibility of a withdrawal of consent at any time for any reason.

Qigong training. During 4 days of training, all participants were grouped together, were similarly nourished, and had similar circadian rhythms. Everyone was subjected to identical training and performed a qigong exercise programme under instructor guidance. All of the women had a normal rest value of heart rate (HR between 70-90), and during the training programme they were obliged to ensure that the HR did not exceed more than $30 \%$ of the resting value. Each day, participants were trained for 8 hours (4 hours for a system called " 5 hand movements," and 4 hours of meditation). The "system called 5 hand movements or 6 secret wards" exercises focused on the performance of low, soft movements, with deep relaxation of the muscles and slow, deep, breathing focusing on suitable circulation circuits: liver, lung, heart, kidney, spleen, and pancreas. Meditations were performed in either the standing position "big tree" (1-2 hours) or sitting position (2-3 hours) while participants focused on selected points called "dan tien". The remaining time was spent on meals and rest. Exercises were conducted daily according to the following schedule (Tab. 1):

Table 1. Detailed characteristic of 4 days Qigong training.

\begin{tabular}{lcc}
\hline \multirow{2}{*}{ Time of day } & $\begin{array}{c}\text { Duration of } \\
\text { training (min) }\end{array}$ & Thursday-Friday \\
\hline 6-6.30 a.m. & 30 & Kind of activity \\
\hline 7-8 a.m. & 60 & Wake-up \\
\hline 8-10 a.m. & 120 & Wreakfast break \\
\hline $10-13$ a.m. & 150 & System called "5 hand movments or \\
6 secret wards"
\end{tabular}

Genetic research. $3 \mathrm{ml}$ of venous blood for genetic research was collected twice. The first and second collections were performed immediately before and after the experiment, respectively. Blood was placed in the tubes allowing separation (BD Vacutainer $\mathrm{CPT}^{\mathrm{TM}}$ ). The remaining $\mathrm{PMBC}$ were lysed using Fenozol (A \& A Biotechnology, Gdynia, Poland). Further isolation of RNA was carried out by the chemical method outlined by Chomczyński and Sacchi [26]. Purity and concentration of the isolated RNA was determined by spectrophotometry (Eppendorf BioPhotometer Plus, Germany). cDNA synthesis from 2 micrograms of RNA was performed using Transcriba Kit (Roche, Departmend Poland) with oligo dT hexamers. For the analysis of gene expression, Real-Time PCR (Applied Bioststem Step One, Lifetechnologies,Poland) was applied 3 times for the same samples using a LightCycler polymerase (Roche, Poland). The temperature-time profile of the reaction was consistent with the manufacturer's instructions. For each reaction, melt curve analysis was performed. The tubulin B gene (TUBB) 
was used as a housekeeping gene. To amplify the genes, the following primer sequences were applied:

\section{TUBB reverse: TCTGTCGGCTCCGCTCTGAGAT TUBB forward: ACTCCCGTTGTCCCAAGGCTTC HSPA1A reverse: TTCGGAGAGTTCTGGGATTGTA HSPA1A forward: TGGACTGTTCTTCACTCTTGGC IL6 reverse: GACATCAAGGCGCATGTGAAC IL6 forward: TCCACGGCCTTGCTCTTGTTT IL10 reverse: AATTCGGTACATCCTCGACGG IL10 forward: GAATCCAGATTGGAAGCATCC HSF1 reverse: CAGGAGCTTGGAGTCCATGCA HSF1 forward: GAGCAGCTCCTTGAGAACATC $N F-k B$ reverse: GATCCCATCCTCACAGTGTTT $N F-k B$ forward: TGGACTACCTGGTGCCTCTA}

Statistical analysis. Descriptive statistics included the mean \pm SD for all measured variables. The normality of distribution was checked with the Shapiro-Wilk test. Gene expression data were collected and relative gene expression analysed using Excel 2010. In order to calculate the level of gene expression, the method of Schmitten and Livak [27] was used, and data were then transformed from logarithm 2 $\left(2^{\wedge}\right)$ to a linear value. To assess the statistical significance of gene expression changes before and after exercise (WAnT), a repeated measures analysis of variance (ANOVA) was used. To determine the differences in gene expression before and after the training period, a paired t-test was calculated. All calculations and graphics were performed using GraphPad Prism 6.0 (ftx.pl/program/graphpad-prism). Differences were considered to be statistically significant at the level of $\mathrm{p} \leq 0.05$.

\section{RESULTS}

After 4 days of qigong training, a significant decrease in the expression of CCL 2 and NF- $k B$ mRNA ( $\mathrm{p}=0.02$ and $\mathrm{p}=0.002$, respectively) was observed, while $I L 10 \mathrm{mRNA}$ significantly increased in the same time frame ( $\mathrm{p}=0.0004)$ (Fig. 1A). Genes associated with apoptosis, HSF1 and HSPA1A mRNA, showed an increase in their expression. However, these changes were not significant (Fig. 1B).

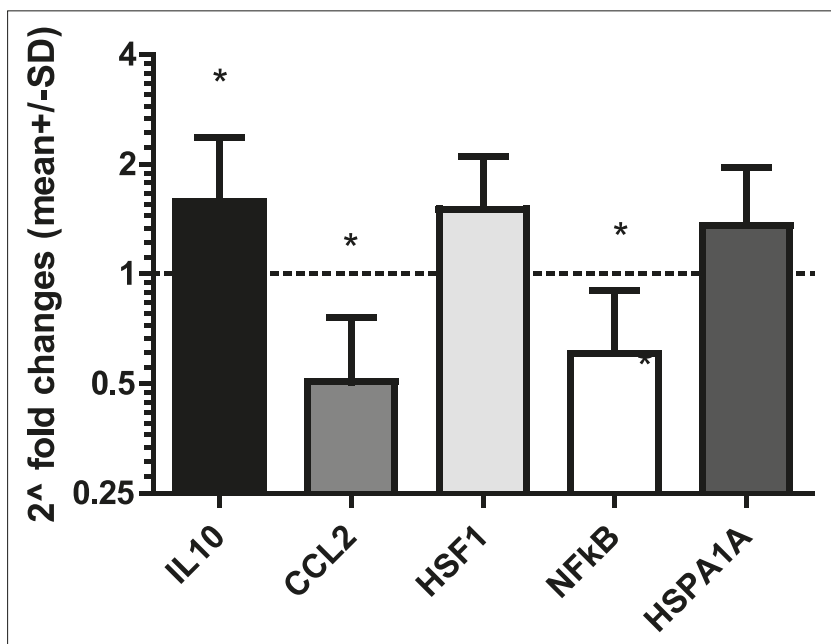

Figure 2. $2^{\wedge}$ fold changes in expression tested genes $\left({ }^{*}\right.$ significant changes in expression)

Opposite directions of change in the expression of 2 genes associated with inflamation and heat shock proteins were observed (Fig. 2). NF-kB and CCL2 mRNA significantly decreased $\left(2^{\wedge} 0.6\right.$ fold, $\mathrm{p}=0.002$ for $N F k B$ and $2^{\wedge} 0.5$ fold $\mathrm{p}=0.02$ for CCL2 m-RNA). An anti-inflammatory effect of this type of training was also observed, as IL10 mRNA was significantly higher after the training period $\left(2^{\wedge} 1.58\right.$ fold, $\mathrm{p}=0.0004)$.

$2^{\wedge}$ expression higher than 1 indicates an increase and less than lindicates a decrease. $2^{\wedge}$ fold $=1-$ no changes in expression.

\section{DISCUSSION}

To the authors' knowledge, this is the first study to investigate the effects of qigong on gene expression associated with cellular stress response in PMBC in healthy women. 4 days of qigong training in this study resulted in a significant decrease in NF- $k B$ and CCL2 mRNA, as well as a significant increase in IL10 mRNA. A slight upregulation of HSF1 and HSPA1A mRNA was also detected. The level of IL6 mRNA in PMBC was too low to be determined and was not marked. According

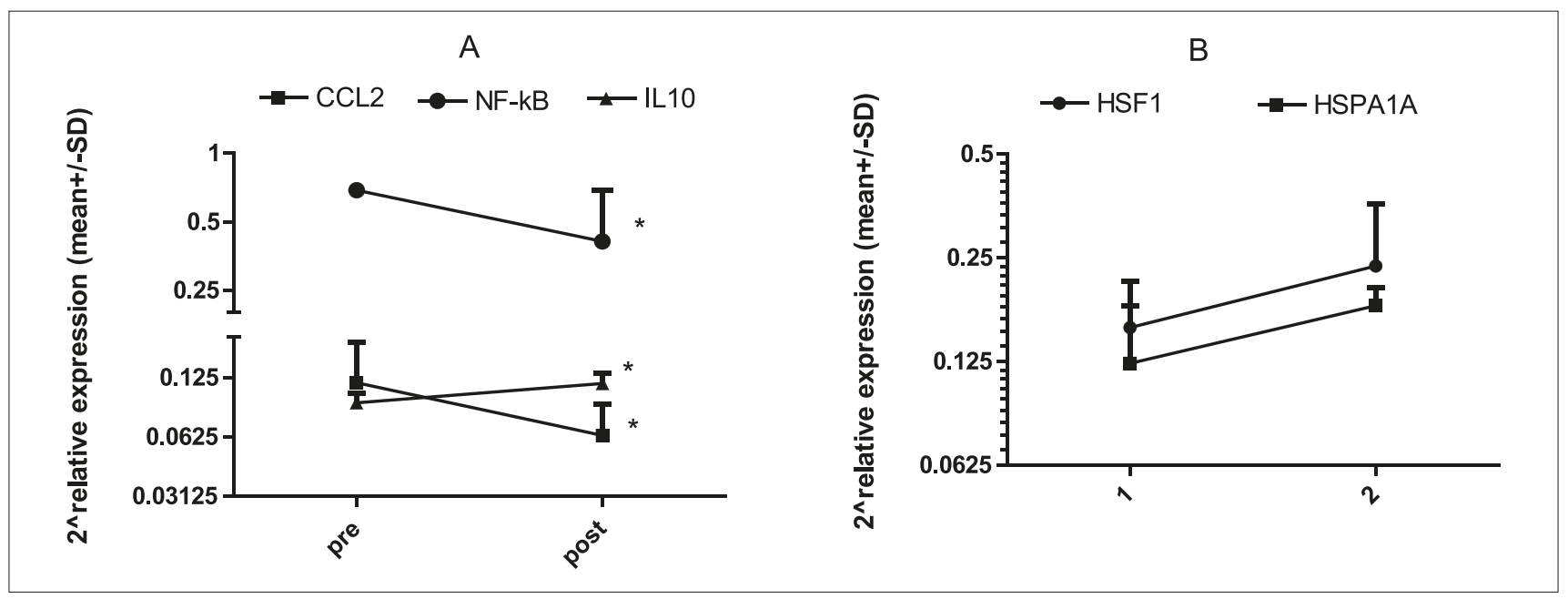

Figure 1. Changes in the relative expression $(2 \wedge)$ of genes associated with inflammation $(1 \mathrm{~A})$ and heat shock protein $(1 \mathrm{~B})$. Pre- rest value, post - value after training. $(*$ significant changes) 
to Berson [28], qigong induces a relaxation response (RR) which was confirmed by changes in the genes associated with inflammation.

Cellular stress response in women differs from the response in men. Diverse sensitivity to stress manifests itself more commonly in depressive and anxiety disorders in women [29-31]. These differences are associated with sex hormones, specifically estrogen, as evidenced by the decrease in postmenopausal symptoms [32]. Furthermore, chronic psychosocial stress has been associated with accelerated aging at the cellular level [14]. Currently, it is well known that this stress causes a decreased anti-oxidant capacity, and increased oxidative stress [33]. These changes could easily induce the expression of genes associated with stress response $[34,35]$. Upregulation of $N F-k B$ and proinflammatory cytokines and their receptors has been well documented. Therefore, all forms of training in which genes associated with stress response are downregulated have a positive health effect. Li et al. [18] reported that qigong can be useful in the reduction of gene expression associated with inflammation, a finding confirmed in the presented study. Additionally, the reduction of expression of $N F-k B$ and enhancement of IL10 $m$-RNA expression was similar to those obtained during physical activity, and comparable to the direction of adaptation changes in response to exercise. According to Fisher et al. ${ }^{36}$ and Ziemann et al. [37], the adaptive effect of exercise decreases pro-inflammatory cytokines and increases anti-inflammatory cytokines. These results suggest that qigong is very useful in populations that have limited exercise tolerance.

There is also data available in the subject literature which shows an induction of apoptosis caused by qigong in different cells such as colorectal cancer cells [10,38] and [39]. In the presented study, upregulation of HSF-1 mRNA and antiapoptotic HSPA1A mRNA were also observed. These findings indicate that (1) the HSF1-dependent pathway in PMCB had been slightly activated and (2) HSPA1A mRNA was slightly upregulated, although less compared to those changes caused by physical effort [40].

Finally, all the indicated changes consisting in the reduction of inflammation and elevation of gene expression associated with apoptosis were noticeable in the PMBC collected from the healthy women. This suggests that qigong training is important for relaxation, not only for men but also for women, and this positive health effect can be confirmed by changes in the PMBC. Furthermore, changes in the tested gene expression are similar to those caused by physical activity indicating that qigong can be useful for people who cannot perform intense physical exercise.

\section{Acknowledgments}

This scientific work was funded by the Jan Kochanowski University funds for research. The authors gratefully acknowledge all the participants involved in the tests.

\section{Author Disclosure Statement}

The funding organization did not affect the study results and no competing financial interests exist.

\section{REFERENCES}

1. Astin JA, Shapiro SL, Eisenberg DM, Forys KL. Mind-body medicine: state of the science, implications for practice. J Am Board Fam Pract. 2003; 16(2): 131-47.

2. Cacioppo JT, Cacioppo S. Social relationships and health: the toxic effects of perceived social isolation. Soc Pers Psychol Compass. 2014; 8(2): 58-72.

3. Cohen L, Cole SW, Sood AK, Prinsloo S, Kirschbaum C, Arevalo JM, Jennings NB, Scott S, Vence L, Wei Q, Kentor D, Radvanyi L, Tannir N, Jonasch E, Tamboli P, Pisters L. Depressive symptoms and cortisol rhythmicity predict survival in patients with renal cell carcinoma: role of inflammatory signaling. PLoS One 2012; 7(8): 42324.

4. Umberson D, Montez JK. Social relationships and health: a flashpoint for health policy. J Health Soc Behav. 2010; 51: S54-S66.

5. Ernst E, Pittler MH, Wider B, Boddy K. Mind-body therapies: are the trial data getting stronger? Altern Ther Health Med. 2007; 13(5): 62-4.

6. Jonas WB, Eisenberg D, Hufford D, Crawford C. The evolution of complementary and alternative medicine (CAM) in the USA over the last 20 years. Forsch Komplementmed. 2013; 20(1): 65-72.

7. Loucks EB, Britton WB, Howe CJ, Eaton CB, Buka SL. Positive associations of dispositional mindfulness with cardiovascular health: the new england family study. Int J Behav Med. 2015; 22(4): 540-550.

8. Kaliman P, Alvarez-Lopez MJ, Cosin-Tomas M, Rosenkranz MA, Lutz A, Davidson RJ. Rapid changes in histone deacetylases and inflammatory gene expression in expert meditators. Psychoneuroendocrinology 2014; 40: 96-107.

9. Yan X, Shen H, Jiang H, Zhang C, Hu D, Wang J, Wu X. External Qi of Yan Xin Qigong differentially regulates the Akt and extracellular signal-regulated kinase pathways and is cytotoxic to cancer cells but not to normal cells. In J Biochem Cell Biol. 2006; 38 : 2102-13.

10. Yan X, Shen H, Jiang H, Hu D, Zhang Ch, Wang J, Wu X. External Qi of Yan Xin Qigong Induces Apoptosis and Inhibits Migration and Invasion of Estrogen-Independent Breast Cancer Cells Through Suppression of Akt/NF-кB Signaling. Cell Physiol Biochem. 2010; 25: 263-70.

11. Połrola P, Góral Półrola J. In search a new methods. Qigong in stuttering therapy. Studia Medyczne 2013; 29 (3): 242-50.

12. Loucks EB, Sullivan LM, D’Agostino Sr, RB, Larson MG, Berkman LF, Benjamin EJ. Social networks and inflammatory markers in the Framingham Heart Study. J Biosoc Sci. 2006; 38(6): 835-842.

13. Yang YC, McClintock MK, Kozloski M, Li T. Social isolation and adult mortality: the role of chronic inflammation and sex differences. J Health Soc Behav. 2013; 54(2): 183-203.

14. Dusek JA,Otu HH, Wohlhueter AL, Bhasin M, Zerbini LF, Joseph MG, Benson H, Libermann TA. Genomic Counter-Stress Changes Induced by the Relaxation Response. PLoS ONE 2008; 3(7): 2576. doi:10.1371/0002576.

15. Bower JE, Irwin MR. Mind-body therapies and control of inflammatory biology: A descriptive review. Brain Behav Immun. 2016; 51: 1-11.

16. Muehsama D, Lutgendorf S, Mills PJ, Rickhi B, Chevalier G, Batf N, Choprac D, Gurfeinh B. The embodied mind: A review on functional genomic and neurological correlates of mind-body therapies. Neurosc Biobehav Rev. 2017; 73: 165-181.

17. Saatcioglu F. Regulation of gene expression by yoga, meditation and related practices: A review of recent studies, Asian J Psych. 2012; 6: 74-77.

18. Li QZ, Li P, Garcia GE, Johnson RJ, Feng L. Genomic profiling of neutrophil transcripts in Asian Qigong practitioners: a pilot study in gene regulation by mind-body interaction. J Altern Complement Med. 2005; 11 (1): 29-39.

19. Antoni MH, Lutgendorf SK, Blomberg B, Carver CS, Lechner S, Diaz A, Stagl J, Arevalo JM, Cole SW. Cognitive-behavioral stress management reverses anxiety-related leukocyte transcriptional dynamics. Biol Psychiatry 2012; 71(4): 366-72.

20. Black DS, Cole SW, Irwin MR, Breen E, St Cyr NM, Nazarian N, Khalsa DS, Lavretsky H. Yogic meditation reverses NF-kappaB and IRF-related transcriptome dynamics in leukocytes of family dementia caregivers in a randomized controlled trial. Psychoneuroendocrinology 2013; 38 (3): 348-55.

21. Creswell JD, Irwin MR, Burklund LJ, Lieberman MD, Arevalo JM, Ma J, Breen EC, Cole SW. Mindfulness-based stress reduction training reduces loneliness and pro-inflammatory gene expression in older adults: a small randomized controlled trial. Brain Behav Immun. 2012; 26(7): 1095-101. 
22. Bower JE, Greendale G, Crosswell AD, Garet D, Sternlieb B, Ganz PA, Irwin MR, Olmstead R, Arevalo J, Cole SW. Yoga reduces inflammatory signaling in fatigued breast cancer survivors: a randomized controlled trial. Psychoneuroendocrinology 2014; 43: 20-9.

23. Kaliman P, Alvarez-Lopez MJ, Cosin-Tomas M, Rosenkranz MA, Lutz A, Davidson RJ. Rapid changes in histone deacetylases and inflammatory gene expression in expert meditators. Psychoneuroendocrinology 2014; 40: 96-107.

24. Sharma H, Datta P, Singh A, Sen S, Bhardwaj NK, Kochupillai V, Singh N. Gene expression profiling in practitioners of Sudarshan Kriya. J Psychosom Res. 2008; 64(2): 213-218.

25. Xia M, Sui Z. Recent developments in CCR2 antagonists. Expert Opinion on Therapeutic Patents. 2009; 19(3): 295-303.

26. Chomczynski P, Sacchi N. Single-step method of RNA isolation by acid guanidinium thiocyanate-phenol-chloroform extraction Anal Biochem. 1987; 162: 156-9.

27. Schmittgen TD, Livak KJ. Analyzing real-time PCR data by the comparative C(T) method. Nat Protoc. 2008; 3: 1101-8.

28. Benson H, Greenwood MM, Klemchuk H. The relaxation response: psychophysiologic aspects and clinical applications. Int J Psychiatry Med. 1975; 6 (1-2): 87-98.

29. Holden C. Sex and the suffering brain. Science. 2005; 308: 1574

30. Kajantie E, Phillips DI. The effects of sex and hormonal status on the physiological response to acute psychosocial stress. Psychoneuroendocrinology. 2006; 31: 151-78.

31. Lundberg U. Stress hormones in health and illness: The roles of work and gender. Psychoneuroendocrinology. 2005; 30: 1017-21.

32. Otte C, Hart S, Neylan TC, Marmar CR, Yaffe K, Mohr DC. A metaanalysis of cortisol response to challenge in human aging: Importance of gender. Psychoneuroendocrinology. 2005; 30: 80-91.
33. Epel ES, Blackburn EH, Lin J, Dhabhar FS, Adler NE, et al. Accelerated telomere shortening in response to life stress. Proc Natl Acad Sci. USA 2004; 101: 17312-15.

34. Morimoto RI, Tissieres A, Georgopoulos C. The biology of heat shock proteins and molecular chaperones. vol 26. Cold Spring Harbor Laboratory Press, 1994.

35. Buttner P, Mosig S, Lechtermann A, Funke H, Mooren FC. Exercise affects the gene expression profiles of human white blood cells J Appl Physiol. 2007; 102: 26-36.

36. Fisher G, et al. High Intensity Interval- vs Moderate Intensity- Training for Improving Cardiometabolic Health in Overweight or Obese Males: A Randomized Controlled Trial PloS one; 2015. 10:e0138853 doi:10.1371/journal.pone.0138853

37. Ziemann E, Zembron-Lacny A, Kasperska A, Antosiewicz J, Grzywacz T, Garsztka T, Laskowski R. Exercise training-induced changes in inflammatory mediators and heat shock proteins in young tennis players J Sports Sci Med. 2013; 12: 282-289.

38. Yan X, Shen H, Jiang H, Zhang C, Hu D, Wang J, Wu X. External Qi of Yan Xin Qigong induces G2/M arrest and apoptosis of androgenindependent prostate cancer cells by inhibiting Akt and NF-kappa B pathways._Mol Cell Biochem. 2008 Mar; 310(1-2): 227-34.

39. Yan X, et al. External Qi of Yan Xin Qigong induces cell death and gene expression alterations promoting apoptosis and inhibiting proliferation, migration and glucose metabolism in small-cell lung cancer cells. Mol Cell Biochem. 2012; 363(1-2): 245-55.

40. Żychowska M, Kemeryte -Raubiene E, Gocentas A, Jascaniniene N, Chruściński G. Changes in leukocyte HSPA1A, HSPB1 mRNA in basketball players after plyometric training. BJPHA 2016; 8(1): 18-24. 